\title{
New catalytic model systems of tyrosinase: fine tuning of the reactivity with pyrazole-based $\mathrm{N}$-donor ligands $\dagger$
}

50, 2298

Received 14th October 2013,

Accepted 8th January 2014

DOI: $10.1039 / c 3 c c 47888 b$

www.rsc.org/chemcomm

Two new $\mathrm{Cu}(1)$ complexes have been synthesized and investigated as model systems of the enzyme tyrosinase. The corresponding ligands are based on a combination of an imine function with two different pyrazole groups. The reactivity of the prepared systems with respect to the conversion of monophenols to the corresponding orthoquinones is investigated. The resulting data are compared to results obtained for other catalytic model systems of tyrosinase.

The ubiquitous type 3 copper enzyme tyrosinase (Ty) catalyses the formation of ortho-quinones, starting from monophenols. The conversion of tyrosine to dopaquinone occurs in a two-step process, starting with an aromatic hydroxylation which is followed by twoelectron oxidation. ${ }^{1,2}$ The formed dopaquinone polymerises spontaneously to the important pigment melanin. ${ }^{3,4}$ The active site of tyrosinase contains a binuclear copper centre, wherein each copper ion is coordinated by three histidine residues. ${ }^{5,6}$ In 2006 Matoba and coworkers published the first crystal structure of a tyrosinase derived from the bacterium Streptomyces castaneoglobisporus. ${ }^{5}$ In the meantime more tyrosinases have been structurally characterized. ${ }^{7}$

Hemocyanins ( $\mathrm{Hc}$ ) and catechol oxidases (CO) are also important type 3 copper proteins, but exhibit reactivities different to tyrosinase. Hemocyanins mediate the oxygen transport in arthropods and molluscs whereas catechol oxidases are responsible for the oxidation of catechols to the corresponding ortho-quinones. ${ }^{6,8,9}$ All of these copper type 3 enzymes have very similar active sites and bind dioxygen as peroxide in a typical $\mu^{2}-\eta^{2}: \eta^{2}$ (side-on bridging) geometry. In the oxy form the oxidation state of copper ions changes from $+\mathrm{I}$ to $+\mathrm{II} .^{1}$

Tyrosinase exhibits monophenolase and diphenolase activity. The monophenolase cycle involves hydroxylation of monophenolic substrates to catechols, which are released as ortho-quinones (Scheme 1). ${ }^{1,6,10}$ In recent years, many low-molecular copper complexes have been synthesized as model systems of tyrosinase. ${ }^{1,11}$

Christian-Albrechts-Universität zu Kiel, Max-Eyth-Straße 2, 24118 Kiel, Germany. E-mail: ftuczek@ac.uni-kiel.de; Fax: +49-(0)431-1520; Tel: +49-(0)431-1410 $\dagger$ Electronic supplementary information (ESI) available. See DOI: 10.1039/ c3cc $47888 \mathrm{~b}$

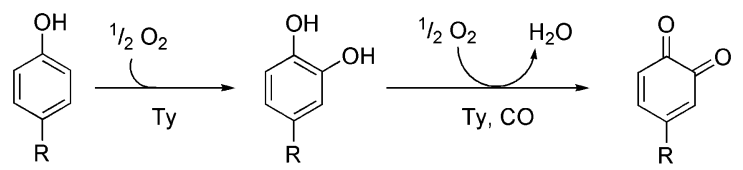

Scheme 1 Conversion of monophenolic substrates to ortho-quinones via catechols (monophenolase and diphenolase activity, respectively).

These compounds can be divided into systems which hydroxylate the ligand framework ${ }^{12-16}$ and those which are able to convert external monophenols to the corresponding ortho-quinones. ${ }^{11,17}$ The first model system exhibiting the latter reactivity in a catalytic fashion was published by Réglier and coworkers. ${ }^{18}$ This binuclear copper(I) complex generates 3,5-di-tert-butyl-o-quinone (DTBQ) from 2,4-di-tert-butyl phenol (DTBP-H) with a turnover number (TON) of 16. The formation of ortho-quinone was detected by using UV/Vis spectroscopy, because ortho-quinones show an intense absorption band in the range of $400-420 \mathrm{~nm} .{ }^{19}$ In 1991 a further system exhibiting stoichiometric as well as weakly catalytic monooxygenation of external phenols was reported by Casella and coworkers. ${ }^{17}$ This year Herres-Pawlis et al. presented a new copper(I) catalyst mediating the hydroxylation of monophenols via a wellcharacterized peroxo intermediate. $^{20}$

In 2010 our group reported the first catalytic model system based on a mononuclear copper(I) complex. ${ }^{11}$ This $\left[\mathrm{Cu}(\mathrm{I}) \mathbf{L}_{\mathbf{p y}} \mathbf{1}\left(\mathrm{CH}_{3} \mathrm{CN}\right)_{2}\right] \mathrm{PF}_{6}$ system ( $c$. Scheme 2) was found to generate DTBQ from DTBP-H with a TON of 18 after 8 hours. More recently we presented a second model system containing a benzimidazole moiety. ${ }^{21}$ With the new

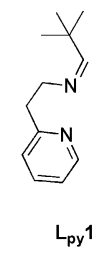

b)

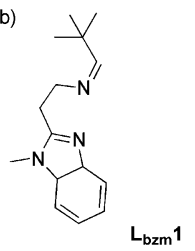

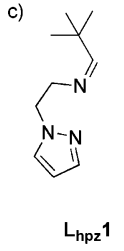

d)

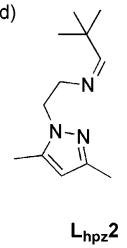

Scheme 2 (a) Ligand $L_{p y} 1$ of the first mononuclear catalytic model system, (b) ligand $\mathbf{L}_{\mathrm{bzm}} \mathbf{1}$ and ligands $\mathbf{L}_{\mathrm{hpz}} \mathbf{1}$ and $\mathbf{L}_{\mathrm{hpz}} \mathbf{2}$ of this study (c and d). ${ }^{11,21}$ 


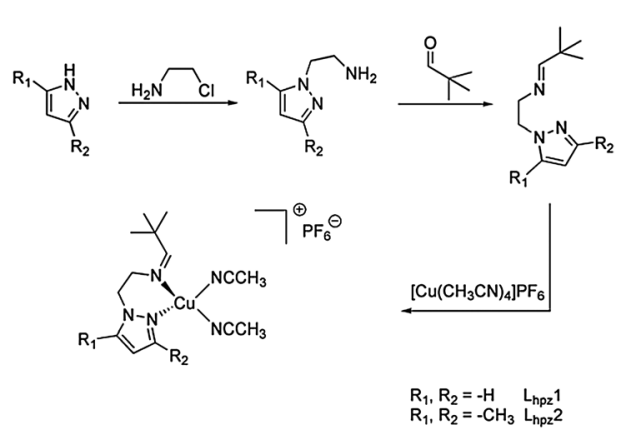

Scheme 3 Syntheses and metalation of the new ligands.

$\mathbf{L}_{\mathbf{b z m}} \mathbf{1}$ system, the TON could be increased to 31, along with a significantly increased turnover frequency. ${ }^{21}$ To further investigate the influence of the heterocyclic group on the reactive properties of our system, we developed two new pyrazole based copper(I) complexes as model systems.

The ligands of both systems contain an imine function terminated by a tert-butyl residue; they only differ with respect to the substituents of the pyrazole moiety ( $\mathbf{L}_{\mathbf{h p z}} \mathbf{1}$ and $\mathbf{L}_{\mathbf{h p z}} 2$; Scheme 2).

Synthesis and reactivity of the new Cu(I) complexes. The two ligands $\mathbf{L}_{\mathbf{h p z}} \mathbf{1}$ and $\mathbf{L}_{\mathbf{h p z}} \mathbf{2}$ were prepared in several steps by using similar procedures (Scheme 3 and ESI $\dagger$ ). For the aminoethylation of the pyrazoles a modification of a literature procedure was used. ${ }^{22}$ The corresponding copper(I) complexes were prepared from tetrakis(acetonitrile)copper(I) hexafluorophosphate under anaerobic conditions.

To investigate the catalytic activity of the pyrazole-based model systems in situ UV/Vis spectroscopy was applied. To this end a $500 \mu \mathrm{M}$ solution of the respective copper(I) complex in dichloromethane was prepared and 50 eq. of DTBP-H and 100 eq. of triethylamine were added. Subsequent oxygenation at ambient temperature was found to result in the formation of DTBQ, as indicated by an absorption band appearing at 407 nm (Fig. 1).

As evident from Fig. 1, the complex $\left[\mathrm{Cu}(\mathrm{I}) \mathbf{L}_{\mathbf{h p z}} \mathbf{1}\left(\mathrm{CH}_{3} \mathrm{CN}\right)_{2}\right] \mathrm{PF}_{6}$ catalyses the formation of 3,5-di-tert-butyl-o-quinone (DTBQ) from the corresponding phenol DTBP-H. For the determination of the turnover number (TON), an extinction coefficient of $\varepsilon=$ $1830 \mathrm{M}^{-1} \mathrm{~cm}^{-1}$ at $407 \mathrm{~nm}$ was applied. ${ }^{19}$ Oxygenation of DTBP-H

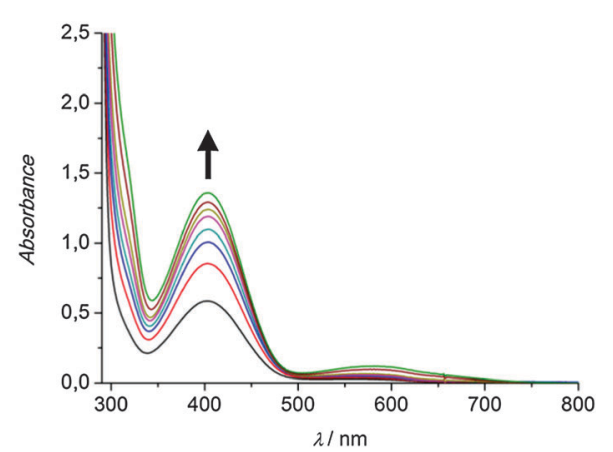

Fig. $1 \mathrm{UV} / \mathrm{Vis}$ spectra of a $500 \mu \mathrm{M}$ solution of the complex $\left[\mathrm{Cu}(1) \mathrm{L}_{\mathrm{hpz}} \mathbf{1}\left(\mathrm{CH}_{3} \mathrm{CN}\right)_{2}\right] \mathrm{PF}_{6}$ in $\mathrm{CH}_{2} \mathrm{Cl}_{2}$ after addition of 50 eq. DTBP-H, 100 eq. $\mathrm{NEt}_{3}$ and oxygenation between $15 \mathrm{~min}$ and $6 \mathrm{~h} ; l=1 \mathrm{~mm}$.

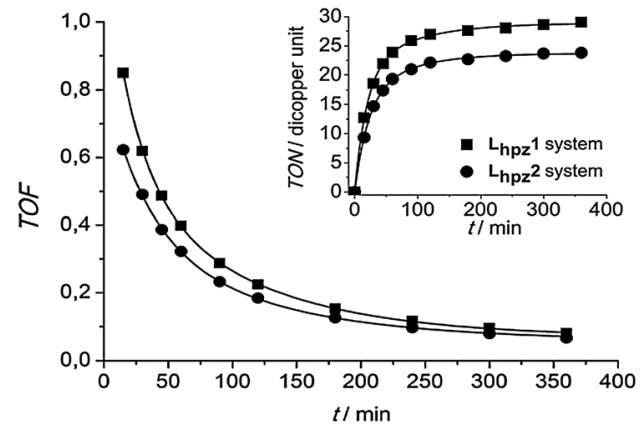

Fig. 2 Turnover frequency as a function of time (15 $\min <t<6$ hours) for the systems $L_{h p z} \mathbf{1}$ and $L_{h p z} 2$; inset: their turnover number per dicopper unit as a function of time.

occurred very fast during the first 100 minutes of reaction and then slowed down, leading to a TON of 29 after 6 hours.

The oxygenation was also performed using the complex $\left[\mathrm{Cu}(\mathrm{I}) \mathbf{L}_{\mathbf{h p z}} 2\left(\mathrm{CH}_{3} \mathrm{CN}\right)_{2}\right] \mathrm{PF}_{6}$. In analogy to the $\mathbf{L}_{\mathbf{h p z}} \mathbf{1}$ system, the formation of DTBQ happened quickly during the first two hours, reaching a TON of 23 after 6 hours. In Fig. 2 the TON and TOF (turnover frequency) of both systems are compared. Importantly, the $\mathbf{L}_{\mathbf{h p z}} \mathbf{1}$ system exhibits both a higher TON (29) and a higher TOF (0.85 $\mathrm{min}^{-1}$ after $15 \mathrm{~min}$ ) as compared to its $\mathbf{L}_{\mathbf{h p z}} \mathbf{2}$ counterpart $\left(\mathrm{TON}=23, \mathrm{TOF}=0.62 \mathrm{~min}^{-1}\right)$. Both systems form most of the quinone during the first $120 \mathrm{~min}$ and become inactive after $\sim 6$ hours.

In order to further prove the formation of DTBQ during the reaction of DTBP with molecular oxygen NMR spectra of the reaction mixture were recorded (Fig. 3). To this end the solutions were quenched with $6 \mathrm{M}$ hydrochloric acid after 30 minutes of oxygenation and extracted with dichloromethane to eliminate the copper ions.

In agreement with similar model systems the resulting NMR spectra revealed signals for DTBQ, DTBP-H and the C-C coupling product 3,3',5,5'-tetra-tert-butyl-2,2'-biphenol ("biphenol", Fig. 3). ${ }^{11,21}$ The signals of DTBP-H, DTBQ and the biphenol are found at a ratio of $51: 18: 31$. This result agrees with the TON of 18 measured after 30 minutes of oxygenation (Fig. 2). For the $\mathbf{L}_{\mathbf{h p z}} \mathbf{2}$ system the corresponding ratio was obtained as 70:15:15 ( $c f$. ESI $\dagger$ ).

Related small-molecule model systems of tyrosinase investigated before ( $c f$. Scheme 2) have already indicated an important

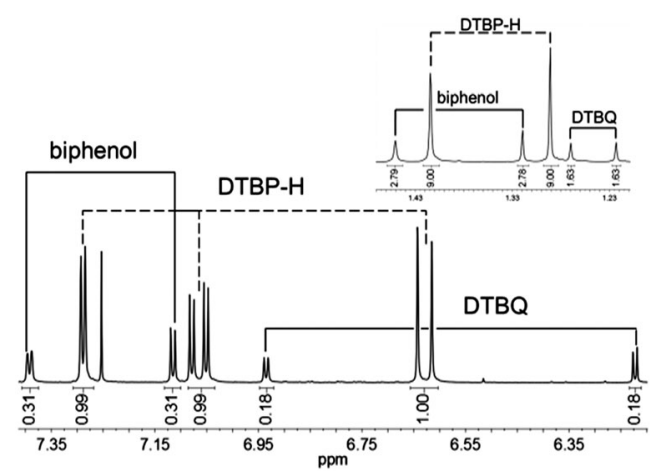

Fig. $3{ }^{1} \mathrm{H}-\mathrm{NMR}$ spectrum of the oxygenation solution after quenching with $\mathrm{HCl}$ (organic phase) for the $L_{h p z} 1$ system. Inset: resonances in the aliphatic region. 


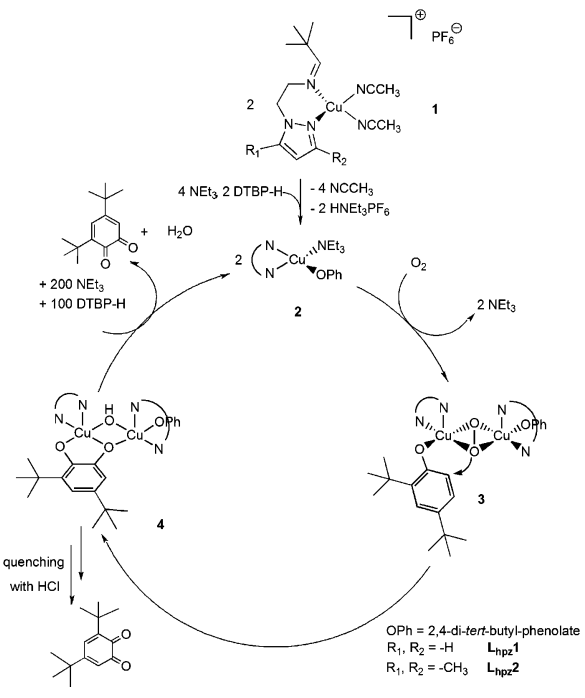

Scheme 4 Proposed catalytic cycle for investigated systems $L_{h p z} 1$ and $\mathrm{L}_{\mathrm{hpz}} \mathbf{2}$ in analogy to model systems $\mathrm{L}_{\mathrm{py}} \mathbf{1}$ and $\mathbf{L}_{\mathrm{bzm}} \mathbf{1}^{11,21}$

influence of the heterocyclic N-donor group on the catalytic activity. ${ }^{11,21}$ Specifically, the $\mathrm{CuL}_{\mathbf{b z m}} \mathbf{1}$ complex was found to mediate the conversion of DTBP-H to DTBQ with a TON of $31,72 \%$ higher than that of $\mathrm{CuL}_{\mathbf{p y}} \mathbf{1}$, and a TOF which was about twice as large as that of the latter complex. This was in part attributed to the well-documented capability of copper-benzimidazole complexes to mediate the ortho-hydroxylation of phenolic substrates. ${ }^{17}$ The new pyrazole-based systems range between the original $\mathbf{L}_{\mathbf{p y}} \mathbf{1}$ system and the $\mathbf{L}_{\mathbf{b z m}} \mathbf{1}$ system; i.e., the methylated $\mathbf{L}_{\mathbf{h p z}} \mathbf{2}$ catalyst is somewhat more active than $\mathbf{L}_{\mathbf{p y}} \mathbf{1}$ and the unsubstituted $\mathbf{L}_{\mathbf{h p z}} \mathbf{1}$ catalyst is almost as active as $\mathbf{L}_{\mathbf{b z m}} \mathbf{1}$. To explain this trend we suggest that electron-rich $\mathrm{N}$-donor ligands promote the hydroxylation reaction by making the peroxo intermediate less stable (Scheme 4, compound 3); i.e. the least reactive pyridine-based system would form the most stable peroxo intermediate whereas the stability of the peroxo intermediate is decreased for the more reactive benzimidazole- or pyrazole based catalysts. In fact, we succeeded in observing the peroxo adduct for the $\mathbf{L}_{\mathbf{p y}} \mathbf{1}$ complex at low temperatures, in contrast to the latter systems ( $c f$. ESI $\dagger$ ). A second possible influence on the reaction rate emerges from the two-electron oxidation of the catecholate adduct $\mathbf{4}$, leading to the quinone.

With respect to the system without substituted pyrazole $\left(\mathbf{L}_{\mathbf{h p z}} \mathbf{1}\right.$; TON $\left.=29\right)$, the TON decreases to 23 for the $\mathbf{L}_{\mathbf{h p z}} \mathbf{2}$ system. In agreement with the above considerations we attribute this effect to (i) increased stabilization of the peroxo adduct and (ii) an increased steric hindrance with respect to coordination of the substrate (phenol) to the peroxo intermediate (Scheme 4).

Two new mononuclear copper(I) complexes containing ligands with pyrazole groups were synthesized as model systems of the enzyme tyrosinase and investigated regarding the conversion of the external substrate DTBP-H to DTBQ, using UV/Vis and NMR spectroscopy. Importantly, the $\mathbf{L}_{\mathbf{h p z}} \mathbf{1}$ system (TON = 29) was found to be more reactive than its $\mathbf{L}_{\mathbf{h p z}} \mathbf{2}$ counterpart (TON $=23$; Table 1 ).

In comparison with the model systems $\mathbf{L}_{\mathbf{b m z}} \mathbf{1}(\mathrm{TON}=31)$ and $\mathbf{L}_{\text {py }} \mathbf{1}$ (TON = 22) published earlier, the new systems have an
Table 1 All mononuclear tyrosinase model systems, ordered by TON for the conversion of DTBP-H to DTBQ at ambient temperature; new systems are indicated in italic font ${ }^{11,21}$

\begin{tabular}{lllll}
\hline System & $\mathbf{L}_{\mathbf{p y}} \mathbf{1}$ & $\mathbf{L}_{\mathbf{h p z}} \mathbf{2}$ & $\mathbf{L}_{\mathbf{h p z}} \mathbf{1}$ & $\mathbf{L}_{\mathbf{b z m}} \mathbf{1}$ \\
\hline TON & 22 & 23 & 29 & 31 \\
TOF@15 min & 0.56 & 0.62 & 0.85 & 0.98
\end{tabular}

intermediate position (Table 1). There seems to be a clear correlation between TON and TOF; i.e., the faster the catalytic reaction, the higher is the product yield. We assume that a higher rate counteracts side reactions which destroy the catalyst, thus leading to a higher catalytic performance.

The authors would like to thank Deutsche Forschungsgemeinschaft (DFG), COST and CAU Kiel for financial support as well as Holger Naggert for support with the measurements.

\section{Notes and references}

1 M. Rolff, J. Schottenheim, H. Decker and F. Tuczek, Chem. Soc. Rev., 2011, 40, 4077.

2 A. W. J. W. Tepper, E. Lonardi, L. Bubacco and G. W. Canters, in Handbook of Metalloproteins, ed. A. Messerschmidt, John Wiley, Chichester, 2010.

3 Á. Sánchez-Ferrer, J. N. Rodríguez-López, F. García-Cánovas and F. García-Carmona, Biochim. Biophys. Acta, Protein Struct. Mol. Enzymol., 1995, 1247, 1.

4 K. E. van Holde, K. I. Miller and H. Decker, J. Biol. Chem., 2001, 276, 15563 .

5 Y. Matoba, T. Kumagai, A. Yamamoto, H. Yoshitsu and M. Sugiyama, J. Biol. Chem., 2006, 281, 8981.

6 H. Decker, T. Schweikardt and F. Tuczek, Angew. Chem., Int. Ed., 2006, 45, 4546.

7 (a) Y. C. Li, Y. Wang, H. B. Jiang and J. P. Deng, Proc. Natl. Acad. Sci. U. S. A., 2009, 106, 17002; (b) M. Sendovski, M. Kanteev, V. S. BenYosef, N. Adir and A. Fishman, J. Mol. Biol., 2011, 405, 227; (c) W. T. Ismaya, H. J. Rozeboom, A. Weijn, J. J. Mes, F. Fusetti, H. J. Wichers and B. W. Dijkstra, Biochemistry, 2011, 50, 5477.

8 K. Selmeczi, M. Réglier, G. Michel and G. Speier, Coord. Chem. Rev., 2003, 245, 191.

9 I. A. Koval, P. Gamez, C. Belle, K. Selmeczi and J. Reedijk, Chem. Soc. Rev., 2006, 35, 814.

10 C. Eicken, C. Gerdemann and B. Krebs, in Handbook of Metalloproteins, ed. A. Messerschmidt, R. Huber, T. Poulos and K. Wieghardt, J. Wiley \& Sons, Chichester, UK, 2001, vol. 2, p. 1319.

11 M. Rolff, J. Schottenheim, G. Peters and F. Tuczek, Angew. Chem., Int. Ed., 2010, 49, 6438.

12 (a) K. D. Karlin, S. Kaderli and A. D. Zuberbühler, Acc. Chem. Res., 1997, 30, 139; (b) M. Rolff, J. N. Hamann and F. Tuczek, Angew. Chem., Int. Ed., 2011, 50, 6924.

13 E. A. Lewis and W. B. Tolman, Chem. Rev., 2004, 104, 1047.

14 L. M. Mirica, X. Ottenwaelder and T. D. P. Stack, Chem. Rev., 2004, 104, 1013.

15 A. De, S. Mandal and R. Mukherjee, J. Inorg. Biochem., 2008, 102, 1170. 16 K. D. Karlin, J. C. Hayes, Y. Gultneh, R. W. Cruse, J. W. Mckown, J. P. Hutchinson and J. Zubieta, J. Am. Chem. Soc., 1984, 106, 2121.

17 L. Casella, M. Gullotti, M. Bartosek, G. Pallanza and E. Laurenti, J. Chem. Soc., Chem. Commun., 1991, 1235.

18 M. Réglier, C. Jorand and B. Waegell, J. Chem. Soc., Chem. Commun., 1990,1752

19 W. Flaig, Th. Ploetz and A. Küllmer, Z. Naturforsch., 1955, 10b, 668. 20 A. Hoffmann, C. Citek, S. Binder, A. Goos, M. Rübhausen, O. Troeppner, I. Ivanović-Burmazović, E. C. Wasinger, T. D. P. Stack and S. Herres-Pawlis, Angew. Chem., Int. Ed., 2013, 52, 5398.

21 J. Schottenheim, N. Fateeva, W. Thimm, J. Krahmer and F. Tuczek, Z. Anorg. Allg. Chem., 2013, 639, 1491.

22 K. Kenji, Jp. Pat. 2010-215610, 2010. 